\title{
MECHANISMS OF SYNTHESIS OF PURINE NUCLEOTIDES IN HEART MUSCLE EXTRACTS ${ }^{1}$
}

\author{
By DAVID A. GOLDTHWAIT ${ }^{2}$ \\ (From the Departments of Biochemistry and Medicine, Western Reserve University, \\ Cleveland, Ohio)
}

(Submitted for publication February 18, 1957; accepted July 18, 1957)

The key role of ATP, a purine nucleotide, in the conversion of chemical energy into mechanical work by myocardial tissue is well established (1, 2). The requirement for purine nucleotides has also been demonstrated in the multiple synthetic reactions which maintain all animal cells in the steady state. Since the question immediately arises whether the purine nucleotides are themselves in a steady state, in which their rates of synthesis equal their rates of degradation, it seems reasonable to investigate first what mechanisms of synthesis and degradation may be operative.

At present, there are three known pathways for the synthesis of purine nucleotides. The first is the synthesis de novo of the purine ring from small molecular weight precursors, such as glycine, formate, $\mathrm{CO}_{2}$, glutamine and aspartic acid (3). The initial steps in this synthesis $(4,5)$ are as follows :

1. Ribose-5-phosphate $+\mathrm{ATP}^{3} \rightarrow$ 5-Phosphoribosylpyrophosphate (PRPP) + AMP.

2. PRPP + glutamine $\rightarrow 5$-phosphoribosylamine (PRA) + glutamic acid.

3. $\mathrm{PRA}+$ glycine $+\mathrm{ATP} \rightarrow$ glycinamide ribotide + ADP + Pi.

Glycinamide ribotide is converted to formyl glycinamide ribotide and then through a series of steps to adenylic and guanylic acids (6).

The second pathway available for the synthesis of nucleotides is via the condensation of a free purine base with PRPP ( 7$)$ :

1 This work was supported by grants from the American Heart Association and the American Cancer Society.

2 This work was done during the tenure of an Established Investigatorship of the American Heart Association.

${ }^{8}$ Abbreviations are as follows: ATP, adenosinetriphosphate; ADP, adenosinediphosphate; AMP, adenosinemonophosphate; IMP, inosinic acid; PRPP, 5-phosphoribosylpyrophosphate; PRA, 5-phosphoribosylamine; $\mathrm{R}-5-\mathrm{P}$, ribose-5-phosphate; $\mathrm{Pi}$, inorganic phosphate; $\mathrm{P}-\mathrm{P}$, pyrophosphate; $\mathrm{NH}_{\mathrm{s}}$, ammonia; and PGA, 3-phosphoglyceric acid.
4. Adenine or Hypoxanthine $+\mathrm{PRPP} \rightarrow \mathrm{AMP}$ or Inosinic Acid (IMP) + P-P.

The third mechanism of synthesis is through the phosphorylation of a purine nucleoside $(8,9)$ :

5. Adenosine + ATP $\rightarrow$ AMP + ADP.

Several enzymatic mechanisms are known which result in the degradation of purine nucleotides and nucleosides. The deamination of adenylic acid is well known (10):

6. $\mathrm{AMP} \rightarrow \mathrm{IMP}+\mathrm{NH}_{3}$.

Non-specific phosphatases (11) as well as specific 5'-nucleotidases (12) have been described which result in dephosphorylation:

7. AMP $\rightarrow$ Adenosine + Phosphate $(\mathrm{Pi})$.

Adenosine can be converted by the enzyme, nucleoside phosphorylase (13), to the free base and a sugar derivative:

8. Adenosine or Inosine $+\mathrm{Pi} \rightarrow$ Adenine or $\mathrm{Hy}$ poxanthine + Ribose-1-Phosphate.

Finally, adenosine may be converted to inosine by an enzyme adenosine deaminase (14):

9. Adenosine $\rightarrow$ Inosine $+\mathrm{NH}_{3}$.

The main purpose of the experiments reported in this paper is to indicate which of the enzymes that catalyze the synthesis of purine nucleotides are present in heart muscle extracts. Observations on some of the degradative steps are also presented.

\section{EXPERIMENTAL}

Ensyme preparation. Three fresh pig hearts were maintained at $0^{\circ} \mathrm{C}$. immediately after removal for onehalf hour. After the fat was removed, they were ground together in a refrigerated electric meat grinder. Three hundred $\mathrm{Gm}$. of ground meat was then suspended in $600 \mathrm{ml}$. of $0.05 \mathrm{M}$ potassium phosphate buffer $\mathrm{pH} 7.4$ and homogenized for 30 seconds in a Waring blendor with a Variac setting of 60 volts. The fluid portion of the homogenate was squeezed through two layers of cheese cloth and centrifuged in a Sorvall Centrifuge (Type SS-1) powered by 60 volts for 15 minutes. A portion of the supernatant solution was kept frozen at $-13^{\circ} \mathrm{C}$. and the remainder was dialyzed against 20 liters 
of distilled water for 18 hours. To the dialyzed enzyme, potassium phosphate buffer $\mathrm{pH} 7.4$ was added to make a final concentration of $0.05 \mathrm{M}$. All operations were carried out at $+2^{\circ} \mathrm{C}$. The enzyme solution was then $1 \mathrm{y}-$ ophilized and the dry powder was stored at $-13^{\circ} \mathrm{C}$. Prior to each experiment, the dry powder was dissolved in water. Fifty $\mathrm{mg}$. of powder per $\mathrm{ml}$. resulted in a protein concentration of $28.5 \mathrm{mg}$. per $\mathrm{ml}$.

Substrates. Adenine-8- $C^{16}$ and adenosine-8- $C^{16}$ were obtained from the Schwarz Laboratories. Adenine-8- $C^{4}$ was deaminated to hypoxanthine-8- $C^{*}$ by a modification of the method of Davoll (15). These purine derivatives were diluted with carrier so that the final specific activity was between 3,000 and 4,000 counts per minute per micromole. AMP was synthesized by the method of Eggleston (16). Glycine-1-C $C^{36}$ was synthesized by the method of Sakami, Evans, and Gurin (17) and had a specific activity of 21,500 counts per minute per micromole. PRPP was prepared enzymatically by a slight modification of the procedure of Kornberg, Lieberman, and Simms (18). ATP was purchased from Pabst, Inc., and potassium phosphoglyceric acid (PGA) was prepared from the barium salt as described previously (19).

Methods. All reaction mixtures were incubated at $37^{\circ}$ C. in air. For determination of the amount of glycine-1$\mathrm{C}^{14}$ incorporated into the glycinamide ribotides and other compounds, the reaction filtrate was treated with ninhydrin to decarboxylate the glycine-1-C $C^{14}$, and the remaining radioactivity was counted (19). The column chromatographic isolation of the glycinamide ribotides has been described (20). For the paper chromatographic separation of other compounds, the following solvent systems were employed: a) butanol saturated with water, $15 \mathrm{~N} \mathrm{NH}_{4} \mathrm{OH}(100: 1)$; b) n-propanol, $15 \mathrm{~N} \mathrm{NH}_{4} \mathrm{OH}$, water $(60: 30: 10)$; c) isopropanol, concentrated $\mathrm{HCl}$, $\mathrm{H}_{2} \mathrm{O}(170: 60: 20)$. The amount of nucleotide synthesized from radioactive adenine, hypoxanthine or adenosine was determined by the application of a $0.2 \mathrm{ml}$. aliquot of the reaction filtrate to a $5-\mathrm{cm}$. starting line on Whatman No. 1 paper. The filtrate was chromatographed by the descending method using solvent $A$, which resulted in movement of nucleosides and free bases off the starting line, but no movement of nucleotides. It was necessary to allow the solvent to run off the paper for an estimated front distance of $45 \mathrm{~cm}$. in order to get good separation of some of the nucleosides from the nucleotides. Solvent B was also employed in some experiments as a check on the isolation of nucleotides. It was possible with solvent $B$ to separate the nucleotides into one band containing adenylic acid and another containing inosinic acid, ADP and ATP. After acid hydrolysis of the material from the second band, and rechromatography of the bases in solvent system $A$, the radioactivity of the inosinic acid and a mixture of ADP and ATP could be estimated. Paper electrophoretic separations of nucleotides were done with $0.02 \mathrm{M}$ sodium citrate buffer, $\mathrm{pH}$ 3.5. Radioactive compounds were eluted from the paper by soaking overnight in $3 \mathrm{ml}$. of $0.1 \mathrm{~N} \mathrm{HCl}$. Aliquots were dried on glass planchets for radioactivity determinations by an end-window counter. Other aliquots were used for the determination of spectra and the estimation of the amount of material recovered. An extinction coefficient for AMP and IMP of 14.8 was employed. The results reported in the tables represent single experiments. Preliminary experiments with the different precursors yielded comparable results.

\section{RESULTS}

Synthesis of nucleotides by the de novo pathway

Incubation of glycine-1-C14 with the fresh extract (Table I) and no substrate additions resulted in 0.003 micromole of glycine fixed in one hour. Addition of ribose-5-phosphate (R-5-P), ATP and glutamine increased fixation to 0.006 micromole. Substitution of 5-phosphoribosylpyrophosphate (PRPP) for R-5-P increased fixation by slightly more than three-fold while substitution of 5-phosphoribosylamine (PRA) for PRPP and glutamine again increased fixation by approximately three-fold to 0.066 micromole. It should be emphasized that glycine fixation represents incorporation into any compound in which the glycine is not decarboxylated by ninhydrin. An attempt at identification of the radioactive products by ion exchange chromatography and paper chromatography was unsuccessful. No radioactivity was found at the points of elution of glycinamide ribotide or its formyl derivative. Thus the glycine incorporation, stimulated by purine precursors, could have been in other intermediates and the 0.006 micromole of glycine fixed when R-5-P and glutamine were added probably repre-

TABLE I

Fixation of glycine-1-C 14 in the presence of purine nucleotide precursors*

\begin{tabular}{lc}
\hline \hline Additions & $\begin{array}{c}\text { Glycine } \\
\text { fixed }\end{array}$ \\
\hline & micromoles \\
None & 0.003 \\
R-5-P + glutamine & 0.006 \\
PRPP + glutamine & 0.020 \\
PRA & 0.066 \\
\hline
\end{tabular}

* Each reaction vessel contained: ATP, 0.8 micromole; PGA, 7 micromoles; glycine-1-C ${ }^{14}, 5$ micromoles; $\mathrm{MgCl}_{2}$, 5 micromoles; Tris buffer $\mathrm{pH} 7.0,20$ micromoles; undialyzed pig heart extract, $4.1 \mathrm{mg}$. protein. Additions were: $\mathrm{R}-5-\mathrm{P}, 5$ micromoles; glutamine, 5 micromoles; PRPP, 1.2 micromoles; PRA, approximately 1 micromole. The final volume was $1 \mathrm{ml}$. and the reaction mixture was incubated for 1 hour at $37^{\circ} \mathrm{C}$. 
TABLE II

Synthesis of nucleotides from $C^{14}$ adenine and $P R P P$ *

\begin{tabular}{|c|c|c|c|c|}
\hline $\begin{array}{c}\text { Experi- } \\
\text { ment }\end{array}$ & Conditions & Time & $\begin{array}{l}\text { C14 } \\
\text { adenine } \\
\text { incor- } \\
\text { porated }\end{array}$ & $\begin{array}{c}\text { U.V. } \\
\text { abeorb- } \\
\text { ing } \\
\text { material }\end{array}$ \\
\hline & & $\min$. & $\begin{array}{l}\text { micro- } \\
\text { moles }\end{array}$ & $\begin{array}{l}\text { micro } \\
\text { moles }\end{array}$ \\
\hline $\begin{array}{l}1 \\
2\end{array}$ & $\begin{array}{l}\text { Undialyzed Extract } \\
\text { Undialyzed Extract + PRPP } \\
\text { Undialyzed Extract + PRPP } \\
\text { Dialyzed Extract + PRPP }\end{array}$ & $\begin{array}{l}60 \\
60 \\
60 \\
60\end{array}$ & $\begin{array}{l}0.11 \\
0.17 \\
0.13 \\
0.20\end{array}$ & \\
\hline 3 & $\begin{array}{l}\text { Dialyzed Extract + PRPP } \\
\text { Dialyzed Extract + PRPP } \\
\text { Dialyzed Extract + PRPP } \\
\text { Dialyzed Extract + PRPP }\end{array}$ & $\begin{array}{l}15 \\
30 \\
45 \\
60\end{array}$ & $\begin{array}{l}0.035 \\
0.074 \\
0.112 \\
0.164\end{array}$ & $\begin{array}{l}0.182 \\
0.240 \\
0.288 \\
0.360\end{array}$ \\
\hline
\end{tabular}

* Each reaction vessel contained : adenine-8-C 14,1 micromole; $\mathrm{MgCl}_{2}, 2.5$ micromoles; Tris buffer $\mathrm{pH}$ 7.0, 20 micromoles; dialyzed heart muscle extract, $5.7 \mathrm{mg}$.; PRPP addition, 0.75 micromole. The final volume was $0.50 \mathrm{ml}$. and vessels were incubated at $37^{\circ} \mathrm{C}$.

sents a maximum value for de novo synthesis under these conditions.

Synthesis of nucleotides by the reaction of purine bases with PRPP

All of the experimental results presented in Tables II and III indicate that an enzyme is present in heart muscle which catalyzes the synthesis of purine nucleotides from PRPP and adenine or hypoxanthine. In experiment 1 , Table II, in undialyzed extracts, addition of PRPP increased synthesis by 55 per cent. Dialyzed extract (experiment 2) appeared to be more active than un-

TABLE III

Synthesis of mucleotides from $C^{14}$ adenine, $C^{14}$ hypoxanthine, $P R P P$ and $R-5-P$ *

\begin{tabular}{ccc}
\hline & Conditions & $\begin{array}{c}\text { Cus } \\
\text { purine } \\
\text { incor- } \\
\text { porated }\end{array}$ \\
\hline & & $\begin{array}{c}\text { micro- } \\
\text { ment }\end{array}$ \\
& & moles \\
1 & Adenine + R-5-P + 0.4 micromole ATP & 0.047 \\
& Adenine + R-5-P + 0.8 micromole ATP & 0.023 \\
& Adenine + R-5-P + 2.0 micromoles ATP & 0.020 \\
& Adenine + PRPP & 0.160 \\
2 & Adenine + PRPP & 0.160 \\
& Hypoxanthine + PRPP & 0.130
\end{tabular}

* Each reaction vessel contained $\mathrm{MgCl}_{2}, 2.5$ micromoles; Tris buffer $\mathrm{pH} 7.0,20$ micromoles; and dialyzed heart muscle extract, $5.7 \mathrm{mg}$. Additions were $R-5-P, 2.5$ micromoles; ATP as indicated in table; PGA, 14 micromoles; PRPP, 0.75 micromole; adenine-8-C ${ }^{14}, 0.98$ micromole; hypoxanthine-8-C14, 0.70 micromole in a final volume of $0.50 \mathrm{ml}$. dialyzed extract. Synthesis proceeded in a linear fashion (experiment 3) under these conditions for at least one hour. That the $\mathrm{C}^{\mathbf{1 4}}$ incorporation represents net synthesis rather than exchange is suggested by the net increase with time of nucleotide material as determined by optical density (O.D.) at $260 \mathrm{~m} \mu$. This increase probably represents synthesis of purine nucleotides, mainly from the $\mathrm{C}^{14}$ adenine-PRPP reaction, and secondarily from some unlabeled precursor.

When ribose-5-phosphate and ATP were substituted for PRPP, synthesis of purine nucleotides was effective (Table III, experiment 1). There appeared to be an optimal level of ATP as was indicated by Kornberg, Lieberman, and Simms using a pigeon liver enzyme (18). Not only is adenine utilized in the synthetic reaction, but also hypoxanthine can be incorporated (Table III, experiment 2).

The nucleotide products recovered from the enzymatic reaction between adenine and PRPP were identified as adenylic acid and inosinic acid. In Table IV, it is clear from the total amounts recovered that the main product was adenylic acid. Furthermore the higher specific activity of adenylic acid suggests that it is the precursor of inosinic acid. Adenylic acid was identified chromatographically by its movement in solvent system B, by its movement on paper electrophoresis, and by hydrolysis and identification of the free base as adenine in solvent system $A$. Inosinic acid, the only nucleotide product of the reaction between hypoxanthine and PRPP, was identified by paper chromatography in solvent system $B$, by spectra, and by movement in paper electrophoresis at $\mathrm{pH}$ 3.5.

\section{Synthesis of nucleotides from adenosine and ATP}

It is evident from the experimental results presented in Table $\mathrm{V}$, that an adenosine kinase exists in heart muscle. Experiment 1 shows the synthesis of nucleotide from $\mathrm{C}^{14}$ adenosine as a function of time. Under these conditions, the synthesis is not linear. This is probably not due to insufficient ATP, as an ATP regenerating system (PGA and the required enzymes) is present, but is more likely due to levels of adenosine insufficient to saturate the enzyme because of the strong competing reaction catalyzed by adenosine 
deaminase. If one assumes the enzyme is saturated for the first 15 minutes, then thic minimum rate of synthesis per hour is 0.37 micromole. Results of experiment 2 indicate that ATP is required for synthesis of nucleotides from $\mathrm{CH}$ adenosine. Isolation of $\mathrm{C}^{\mathbf{4}}$ inosine and hypoxanthine (experiment 2) after a onc-hour incubation is strong evidence for the presence of adenosine deaminase and nucleoside phosphorylase. No $\mathrm{C}^{14}$ adenosine was recovered. The total $\mathrm{C}^{14}$ recoveries in this experiment were 87 and 90 per cent. In experiment 2 the amount of nucleotide synthesis is decreased because one-half the amount of $\mathrm{C}^{14}$ substrate was employed. Results of experiment 3 indicate that different levels of ATP are not critical in the reaction. Again radioactive inosine and hypoxanthine were recovered as well as 0.26 micromole of an unidentified fraction. The total $\mathrm{C}^{14}$ recovery in this experiment was 75 per cent. The synthesis of $\mathrm{C}^{14}$-labeled nucleotides from $\mathrm{C}^{14}$ adenosine could go via inosine and hypoxanthine with condensation of the latter with PRPP, as indicated in Table III. Since, in experiment 4, a pool of non-radioactive hypoxanthine did not decrease the $\mathrm{C}^{\mathbf{1 4}}$ incorporated into nucleotides, it may be concluded that hypoxanthine is not an intermediate in the conversion of adenosine to a nucleotide. Non-radioactive inosine and adenine gave similar results.

The radioactive products of the reaction between $\mathrm{C}^{14}$-adenosine and ATP were identified by paper chromatography of the nucleotides in sol-
TABEE IV

Nualeotide products of the reaction between $P R P P$ and $C^{14}$ adenine*

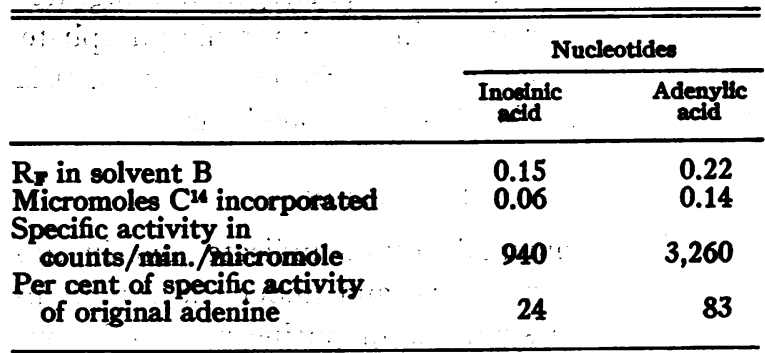

* Products were recovered from an experiment similar to that in Table III, experiment 2.

vent $B$, and of the free bases of the nucleotides in solvent $A$, and also by paper electrophoresis of the nucleotides. After a one-hour incubation, approximately 10 per cent of the total $C^{14}$ recovered was adenylic acid, 10 per cent was inosinic acid, and 80 per cent was a mixture of ADP and ATP.

\section{Dephosphorylation of adenylic acid}

A final experiment was done to demonstrate that an enzyme is present in heart muscle extract which can liberate phosphate from adenylic acid. Six and three-tenths micromoles of adenosine-5-phosphate labeled with $\mathrm{P}^{32}$ were incubated with 5 micromoles of $\mathrm{MgCl}_{2}, 20$ micromoles of Tris buf-

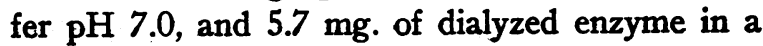
volume of $0.8 \mathrm{ml}$. for 60 minutes. The TCA reaction filtrates of the zero time control and the incubation mixture were then chromatographed in

TABLE V

Synthésis of nucleotides from $C^{u}$ adenosine and $A T P$ *

\begin{tabular}{|c|c|c|c|c|c|}
\hline \multirow[b]{2}{*}{$\begin{array}{l}\text { Experi- } \\
\text { ment }\end{array}$} & \multirow[b]{2}{*}{ Conditions } & \multirow[b]{2}{*}{ Time } & \multicolumn{3}{|c|}{ Cu-labeled compound recovered } \\
\hline & & & Nucleotide & Inosine & $\begin{array}{c}\text { Hypo- } \\
\text { canthine }\end{array}$ \\
\hline & & minutes & & micromoles & \\
\hline 1 & $\begin{array}{l}\text { Adenosine }(3.9) \dagger+\text { ATP }(2.0) \\
\text { Adenosine }(3.9)+\text { ATP }(2.0) \\
\text { Adenosine }(3.9)+\text { ATP }(2.0)\end{array}$ & ) & $\begin{array}{l}0.092 \\
0.104 \\
0.134\end{array}$ & & \\
\hline 2 & $\begin{array}{l}\text { Adenosine (1.8) } \\
\text { Adenosine (1.8) + ATP (0.8) }\end{array}$ & $\begin{array}{r}60 \\
60\end{array}$ & $\begin{array}{l}0 \\
0.048\end{array}$ & $\begin{array}{l}0.99 \\
1.08\end{array}$ & $\begin{array}{l}0.57 \\
0.51\end{array}$ \\
\hline 3 & Adenosine (3.9) + ATP $(0.8)$ & 60 & 0.12 & 1.90 & \\
\hline 4 & $\begin{array}{l}\text { Adenosine }(1.8)+\text { ATP }(2.0) \\
\text { Adenosine }(1.8)+\text { + ATP }(2.0) \\
\text { Adenosine }(1.8)+\text { ATP }(2.0) \\
\text { Adenosine }(1.8)+\text { ATP }(2.0)\end{array}$ & $\begin{array}{l}+ \text { hypoxanthine (5) } \\
+ \text { inosine }(5) \\
+ \text { adenine }(5)\end{array}$ & $\begin{array}{l}0.10 \\
0.067 \\
0.067 \\
0.056\end{array}$ & 1.70 & \\
\hline
\end{tabular}

* The reaction vessels contained additions as indicated, plus $\mathrm{MgCl}_{2}, 2.5$ micromoles; Tris buffer pH 7.0, 20 micromoles; PGA, 14 micromoles; and dialyzed enzyme, $5.7 \mathrm{mg}$. in a final volume of $0.8 \mathrm{ml}$. Incubations were at $37^{\circ} \mathrm{C}$.

† The figures in parentheses represent micromoles. 
solvent $\mathrm{C}$, and sections of this paper were eluted and counted. During the incubation radioactivity was liberated which, on chromatography, migrated in the area corresponding to inorganic phosphate. The amount recovered was the equivalent of 0.22 micromole of $\mathrm{AMP}^{32}$ split in one hour.

\section{DISCUSSION}

The experimental results indicate that in this extract of heart muscle and under the conditions employed, the synthesis of purine nucleotides via the de novo pathway (reactions 1 to 3 , etc.) was less efficient than synthesis via utilization of the free base (reaction 4) or via phosphorylation of adenosine (reaction 5). The incorporation of glycine-1-C $\mathrm{C}^{14}$ into glycinamide ribotide requires at least three enzymatic steps when ribose-5-phosphate, ATP, glutamine and glycine are supplied. At least two steps are required when PRPP is utilized and probably one when PRA is employed (reactions 1 to 3 ). The stimulation of glycine$1-C^{14}$ incorporation in the presence of these substrates suggests that the incorporation noted represents purine precursor synthesis in spite of the fact that neither glycinamide ribotide nor formylglycinamide ribotide were isolated. If the glycine incorporation does represent de novo synthesis, then 0.006 micromole of purine precursors was synthesized in one hour under these conditions when ribose-5-phosphate and glutamine were used.

Spilman (21) has provided isotopic evidence that the acid soluble adenine nucleotides of dog heart muscle are in a dynamic state. Ninety minutes after injection with $\mathrm{C}^{14}$-formate the dog was sacrificed and the acid soluble nucleotides were isolated and counted (counts per minute per $5 \mathrm{mg}$. of purine). Activities were: gastrointestinal tract, 680; heart, 467; kidney, 289; liver, 34 ; while the urine uric acid was 3,150 . The remarkably high activity of the heart could represent exchange of the 2 carbon, de novo synthesis, or possibly synthesis from hypoxanthine made in the liver and transported through the blood. From the experiment it is impossible to conclude which of these mechanisms may be operative, but the high activity does indicate a dynamic state.

The condensation of a free purine base, either adenine or hypoxanthine, with PRPP to form the corresponding nucleotide (reaction 4) occurs readily in cardiac muscle extracts. In experiment 3, Table II, 0.164 micromole of nucleotide was synthesized in one hour. The synthesis of PRPP may be limiting as only 0.047 micromole of nucleotide was synthesized when ribose-5-phosphate and ATP rather than PRPP were employed: This activity, however, is almost ten times the rate of glycine incorporation under somewhat comparable conditions. This enzymatic mechanism which has been shown to be present in skeletal muscle (22) would require either adenine or hypoxanthine. The demonstration of both of these purine bases in the urine of normal humans (23) suggests that they probably are available via the blood stream to cells of the body. Indeed, hypoxanthine has been identified in plasma (24). That these free bases are utilized for nucleic acid synthesis by tissues such as liver and intestine has been demonstrated by in vivo experiments $(25,26)$. It should be noted that hypoxanthine is not utilized by extracts of bone marrow for the synthesis of purine nucleotides (27). No experiments on purine utilization by cardiac muscle are reported and similar experiments on skeletal muscle are conflicting. The observation in the rat that the amino group of muscle adenylic acid was easily labeled with $\mathrm{N}^{15} \mathrm{H}_{3}$ while the ring nitrogens were not (28) suggested that only the amino group was in a dynamic equilibrium. However, when a high level of uniformly labeled $\mathrm{N}^{15}$-adenine was fed, muscle ATP became labeled (24). Comparable levels of labeled hypoxanthine did not result in labeling of the ATP (29). These results suggest that enzymes are present in skeletal muscle for the incorporation of adenine, but that the turnover rate in this tissue is slow.

The conversion of the nucleoside adenosine to a nucleotide, in the presence of ATP and the muscle extract (reaction 5), is indicated in Table V. Assuming the rate of synthesis in the first 15 minutes was maintained for one hour, 0.37 micromole of adenylic acid would be synthesized. This appears to be the most efficient in vitro mechanism. The adenosine needed for this reaction might arise from adenine via reaction 8 . However, the presence of a strong adenosine deaminase, as indicated by the recovery of inosine and hypoxanthine in experiments 2 and 3 , Table V, makes the sig- 
nificance of the adenosine kinase difficult to interpret, but differential cellular localization of these enzymes cannot be ruled out. It is of interest that Lowy, Davoll, and Brown (30) have found considerable incorporation of adenosine-8- $\mathrm{C}^{\mathbf{1 4}}$ and inosine-8-C ${ }^{14}$ into the ATP of skeletal muscle. Thus the more effective pathways for synthesis of nucleotides in heart muscle extracts appear to be the utilization of the free purine base and of adenosine. Which of the three pathways is utilized predominantly in vivo remains to be determined.

With a dynamic state of the nucleotides in heart muscle, one would also expect to find degradative mechanisms operative. An enzyme responsible for deamination of adenylic acid to form ammonia and inosinic acid (reaction 6) was originally described in skeletal muscle (10), but has also been isolated from heart muscle (31). It is most reasonable to suspect that this enzyme was responsible for the recovery of inosinic acid (Table IV). The dephosphorylation of adenylic acid has also been described in heart muscle (31), and evidence is presented in this paper which supports this finding. The enzyme nucleoside phosphorylase (reaction 8 ) is most likely responsible for the appearance of hypoxanthine (Table V, experiments 2 and 3 ). It is clear that a potent adenosine deaminase (reaction 9) (Table V, experiments 2 and 3 ) is present in the pig heart extracts. In view of the ability of adenosine to produce heart block (32) and vasodilatation (33), this enzyme may serve a useful role in protecting and possibly regulating myocardial metabolism.

Thus, enzymatic mechanisms are present for the synthesis and breakdown of nucleotides in heart muscle. The loss of nucleotides from an in vitro heart muscle preparation occurs especially under anaerobic conditions and when there is excess potassium (34). In intact perfused hearts, the appearance of inosine and hypoxanthine in the perfusates associated with decreased $\mathrm{O}_{2}$ tension (35) indicates that under conditions which may pertain to physiopathological states, there may be a loss of nucleotides from the heart muscle. Thus the concept of a dynamic equilibrium of synthesis and degradation of nucleotides in heart muscle and its possible relationship to cardiac function still remain to be explored.

\section{SUMMARY}

1. Mechanisms of synthesis and degradation of purine nucleotides in an extract of pig heart muscle have been explored.

2. In this extract the more active synthetic pathways are via the phosphorylation of adenosine and the condensation of adenine or hypoxanthine with PRPP. De novo synthesis appears less active.

3. Evidence for the dephosphorylation of adenylic acid as well as for the enzymes adenylic acid deaminase, adenosine deaminase, and nucleoside phosphorylase is presented.

\section{ACKNOWLEDGMENTS}

The author is indebted to Mrs. Jean Tsau and Miss Betty Einsel for very capable technical assistance, to Dr Robert Berne for many helpful suggestions, and to Drs. Harland G. Wood and G. Robert Greenberg for their support and the excellent facilities that were available.

\section{REFERENCES}

1. Szent-Gyorgyi, A., Chemical Physiology of Contraction in Body and Heart Muscle. New York, Academic Press, 1953.

2. Mommaerts, W. F. H. M., Muscular Contraction. A Topic in Molecular Physiology. New York, Interscience Publishers, 1950.

3. Buchanan, J. M., Levenberg, B., Flaks, J. G., Glander, J. A., in A Symposium on Amino Acid Metabolism, W. D. McElroy and H. B. Glass, Eds. Baltimore, Johns Hopkins Press, 1955.

4. Goldthwait, D. A., Peabody, R. A., and Greenberg, G. R., On the mechanism of synthesis of glycinamide ribotide and its formyl derivative. J. Biol. Chem., 1956, 221, 569.

5. Goldthwait, D. A., 5-phosphoribosylamine, a precursor of glycinamide ribotide. J. Biol. Chem., 1956, 222, 1051.

6. Carter, C. E., Metabolism of purines and pyrimidines. Ann. Rev. Biochem., 1956, 25, 123.

7. Kornberg, A., Lieberman, I., and Simms, E. S., Enzymatic synthesis of purine nucleotides. J. Biol. Chem., 1955, 215, 417.

8. Kornberg, A., and Pricer, W. E., Jr., Enzymatic phosphorylation of adenosine and 2,6-diaminopurine riboside. J. Biol. Chem., 1951, 193, 481.

9. Caputto, R., The enzymatic synthesis of adenylic acid; adenosinekinase. J. Biol. Chem., 1951, 189, 801.

10. Schmidt, G., Uber fermentative Desaminierung in Muskel. Ztschr. f. physiol. Chem., 1928, 179, 243.

11. Heppel, L. A., Intestinal phosphomonoesterase in Methods in Enzymology, S. P. Colowick and N. O. Kaplan, Eds. New York, Academic Press, 1955, vol. II.

12. Heppel, L. A., and Hilmoe, R. J., "5" nucleotidases 
in Methods in Enzymology, S. P. Colowick and N. O. Kaplan, Eds. New York, Academic Press, 1955, vol. II, p. 546.

13. Kalckar, H. M., Enzymatic synthesis of purine ribosides. J. Biol. Chem., 1947, 167, 477.

14. Kalckar, H. M., Differential spectrophotometry of purine compounds by means of specific enzymes. J. Biol. Chem., 1947, 167, 445.

15. Davoll, J., A synthesis of crotonoside. J. Am. Chem. Soc., 1951, 73, 3174.

16. Eggleston, L. V., Preparation of "P-labelled adenosine-5'-phosphate, inosine-5'-phosphate, and ribose5-phosphate. Biochem. J., 1954, 58, 503.

17. Sakami, W., Evans, W. E., and Gurin, S., Synthesis of organic compounds labeled with isotopic carbon. J. Am. Chem. Soc., 1947, 69, 1110.

18. Kornberg, A., Lieberman, I., and Simms, E. S., Enzymatic synthesis and properties of 5-phosphoribosylpyrophosphate. J. Biol. Chem., 1955, 215, 389.

19. Goldthwait, D. A., and Greenberg, G. R., Some methods for the study of de novo synthesis of purine nucleotides in Methods in Enzymology, S. P. Colowick and N. O. Kaplan, Eds. New York, Academic Press, 1955, vol. II, p. 504.

20. Goldthwait, D. A., Peabody, R. A., and Greenberg, G. R., On the occurrence of glycinamide ribotide and its formyl derivative. J. Biol. Chem., 1956, 221, 555.

21. Spilman, E., The biosynthesis of uric acid in the dog and man. Ph.D. Thesis, Western Reserve Univ., 1953.

22. Saffran, M., Nucleotide synthesis by tissue extracts in Methods in Enzymology, S. P. Colowick and N. O. Kaplan, Eds. New York, Academic Press, 1955, vol. II, p. 501.

23. Weissmann, B., Bromberg, P. A., and Gutman, A. B., Chromatographic investigation of purines in normal human urine. Proc. Soc. Exper. Biol. \& Med., 1954, 87, 257.
24. Guthrie, R., Seidenberg, M., Tuller, M., and Lu, W. C., Use of purine-requiring bacillus subtilis mutants analysis of human blood serum. Federation Proc., 1954, 13, 222.

25. Brown, G. B., Roll, P. M., Plentl, A. A., and Cavalieri, L. F., The utilization of andenine for nucleic acid synthesis and as a precursor of guanine. J. Biol. Chem., 1948, 172, 469.

26. Bennett, L. L., Jr., and Skipper, H. E., In vivo utilization of hypoxanthine and other precursors for synthesis of nucleic acid purines. Arch. Biochem. \& Biophys., 1955, 54, 566.

27. Abrams, R., and Bentley, M., Biosynthesis of nucleic acid purines. Arch. Biochem. \& Biophys., 1955, 58, 109.

28. Kalkar, H. M., and Rittenberg, D., Rejuvenation of muscle adenylic acid nitrogen in vivo studied with isotopic nitrogen. J. Biol. Chem., 1947, 170, 455.

29. Getler, H., Roll, P. M., Tinker, J. F., and Brown, G. B., A study of the metabolism of dietary hypoxanthine and xanthine in the rat. J. Biol. Chem., 1949, 178, 259.

30. Lowy, B. A., Davoll, J., and Brown, G. B., The utilization of purine nucleosides for nucleic acid synthesis in the rat. J. Biol. Chem., 1952, 197, 591.

31. Nechiporenko, Z. Yu, and Pogrebinska, E. N., The deamination of adenylic acid by heart muscle. Ukrain. Biokhim. Zhur., 1949, 21, 150.

32. Rand, M., Stafford, A., and Thorp, R. H., The potentiation of the action of adenosine on the guinea pig heart by ouabain. J. Pharmacol. \& Exper. Therap., 1955, 114, 119.

33. Green, H. N., and Stoner, H. B., Biological Actions of the Adenine Nucleotides. London, Lewis and Co., 1950.

34. Khairallah, P. A., and Mommaerts, W. F. H. M., Nucleotide metabolism in cardiac activity. Circ. Research, 1953, 1, 8.

35. Berne, R. M., Personal communication of unpublished observations. 